\begin{tabular}{|c|l|}
\hline Title & $\begin{array}{l}\text { Characteristics of proteins involved in membrane fouling in membrane bioreactors (MBRs) treating municipal } \\
\text { wastewater: the application of metaproteomic analyses }\end{array}$ \\
\hline Author(s) & Miyoshi, Taro; A izawa, Tomoy asu; Kimura, Katsuki; W atanabe, Y oshimasa \\
\hline Citation & $\begin{array}{l}\text { Desal ination and Water Treatment, 34(1-3), 150-155 } \\
\text { https://doi.org/L0.5004/dwt.2011.2894 }\end{array}$ \\
\hline Issue Date & 2011 \\
\hline Doc URL & http:/hdl.handle.net/2115/52017 \\
\hline Type & article (author version) \\
\hline File Information & DWT_Final revision.pdf \\
\hline
\end{tabular}

Instructions for use 


\title{
Characteristics of proteins involved in membrane fouling in membrane bioreactors (MBRs) treating municipal wastewater: the application of metaproteomic analyses
}

\author{
Taro Miyoshi ${ }^{\mathrm{a},}$, Tomoyasu Aizawa ${ }^{\mathrm{b}}$, Katsuki Kimura ${ }^{\mathrm{c}}$ and Yoshimasa Watanabe $^{\mathrm{a}}$ \\ ${ }^{a}$ Center for Environmental Nano and Bio Engineering, Hokkaido University, Sapporo, Japan \\ ${ }^{b}$ Division of Biological Sciences, Hokkaido University, Sapporo, Japan \\ ${ }^{c}$ Division of Built Environmentl, Hokkaido University, Sapporo, Japan \\ *: jms-mbr@eng.hokudai.ac.jp
}

\begin{abstract}
We investigated the relationship between the nature of proteins and their fouling propensities in pilotscale membrane bioreactors (MBRs) treating real municipal wastewater with two-dimensional polyacrylamide gel electrophoresis (2D-PAGE). In 2D-PAGE, proteins are separated based on their isoelectric points and molecular weights, and therefore, information can be obtained on the nature of the proteins. Foulants extracted from fouled membranes at the end of continuous operation and organic matter contained in mixed liquor suspension were analyzed by 2D-PAGE, and the results were compared. This analysis was performed for two identical MBRs operated under different solid retention times (SRT) to investigate the effect of the operating condition on the types of proteins with high fouling propensities. In the MBR operated with a long SRT, the presence of proteins that appeared in the neutral pH range was more pronounced in the extracted foulant. Because the $\mathrm{pH}$ of the mixed liquor suspension was in the range of 6-7 throughout the continuous operation, the difference in protein profiles between the extracted foulant and the organic matter contained in the mixed liquor suspension in the MBR operated with a long SRT can be explained by a decrease in solubility of a protein at its isoelectric point. In contrast, in the MBR operated with a short SRT, the presence of proteins that appeared in the acidic region (pH 3-5) was more prominent in the extracted foulant compared with the organic matter contained in the mixed liquor suspension. The results obtained in this study imply that dominant fouling mechanisms differed depending on the operating condition.
\end{abstract}

Keywords:

Membrane bioreactor; Membrane fouling; Two-dimensional polyacrylamide gel electrophoresis (2DPAGE)

\section{Introduction}

Membrane bioreactors (MBRs) have many advantages over conventional biological wastewater treatment technologies including the high quality of treated water, small footprint, ease of operation, and less excess sludge, and therefore, the number of installations of MBRs is expected to increase [1,2]. For more efficient use of MBRs, however, problems associated with membrane fouling need to be addressed. An understanding of fouling mechanisms including the characteristics of the constituents that cause membrane fouling (foulants) is indispensable for controlling membrane fouling in MBRs. In a number of previous studies, proteins were identified as being one of the major foulants in MBRs [3,4]. At present, however, very little is known about the details of proteins that cause membrane fouling in MBRs. Detailed information on the characteristics of proteins with a higher fouling potential would improve our knowledge on fouling mechanisms in MBRs [5,6].

Two-dimensional polyacrylamide gel electrophoresis (2D-PAGE) is a powerful tool for separating and characterizing proteins. Its applicability for activated sludge systems has been extensively reported in previous publications [7,8]. In 2D-PAGE, proteins are separated based on their isoelectric points and molecular weights. By comparing 2D-PAGE gel images of foulants and organic matter contained in mixed liquor suspension, information on the nature of proteins with high fouling propensities can be obtained. In this study, we operated two pilot-scale MBRs fed with real municipal wastewater under different solid retention times (SRT). Protein profiles of organic matter collected from a mixed liquor suspension were 
analyzed by 2D-PAGE. Foulants were extracted from the fouled membranes at the end of the continuous operation, and protein profiles of the extracted foulants were compared with those of organic matter contained in the mixed liquor suspension. On the basis of the results obtained in this study, the relationship between the nature of proteins and their fouling propensities is discussed.

\section{Materials and methods}

\subsection{Sample collection}

The samples were collected from pilot-scale MBRs fed with real municipal wastewater. The pilot-scale MBRs were installed at an existing municipal wastewater treatment facility in Sapporo, Japan. Two identical MBRs (MBRs 1 and 2) were operated in parallel with the same raw wastewater delivered from the inlet of the primary sedimentation basin of the facility. The characteristics of the raw wastewater of this plant can be found elsewhere [9]. The MBRs were equipped with $1.3 \mathrm{~m}^{2}$ of hollow-fiber micro-filtration (MF) membranes (Mitsubishi Rayon Engineering, Tokyo, Japan). The membranes were made of polyvinylidene fluoride (PVDF) and had a nominal pore size of $0.4 \mu \mathrm{m}$. These MBRs were operated with different SRT. The operating conditions other than SRT were exactly the same between the two MBRs. MBR1 was operated with the solid retention time (SRT) of 10 days, while MBR2 was operated with the SRT of 50 days. The hydraulic retention time (HRT) was $5 \mathrm{~h}$ for both reactors. As a result, the mixed liquor suspended solid (MLSS) concentrations of MBR1 and MBR2 were $1.3 \mathrm{~g} / \mathrm{L}$ and $9.8 \mathrm{~g} / \mathrm{L}$, respectively. The biomass was allowed to acclimatize to the operating conditions for more than three months. After acclimatization of biomass had been confirmed, continuous operation of MBRs was initiated with new membranes. Continuous operation of the pilot-scale MBR was continued for 15 days, and organic matter collected during this period was compared with foulants that caused membrane fouling in the continuous operation.

Membrane fouling can be divided into two categories: physically reversible and irreversible fouling [10]. The former type of membrane fouling can be controlled as long as efficient physical membrane cleaning is applied. In contrast, the latter type of membrane fouling develops even when efficient physical cleaning is carried out. It is important to control physically irreversible fouling. Therefore, in this study we focused on analyzing the organic matter that contributes to physically irreversible fouling. Since physically irreversible fouling is mainly caused by dissolved matter [11], we focused on analyzing the profiles of dissolved proteins contained in the mixed liquor suspension. A solution containing dissolved organic matter was obtained by centrifugation ( $4800 \mathrm{rpm}$; $5 \mathrm{~min}$ ) followed by filtration using a membrane filter paper with a pore size of $0.45 \mu \mathrm{m}$. At the end of the continuous operation of the pilot-scale MBR, foulants that were responsible for the development of physically irreversible fouling were extracted from the fouled membranes. To ensure that a cake layer that had accumulated on the membrane was removed, the surface of the fouled membrane was gently wiped with a sponge prior to the extraction of foulant. Foulant was extracted from the fouled membrane by soaking the membranes in a sodium hydroxide solution at $30^{\circ} \mathrm{C}$ for $24 \mathrm{~h}$. The $\mathrm{pH}$ of the extraction solution was set at 12 .

\subsection{Protein preparation}

The methods used to prepare proteins have been described in detail elsewhere [12]. Briefly, solutions containing dissolved proteins in mixed liquor suspension or foulants extracted from fouled membranes were concentrated in a continuously stirred membrane filtration unit, equipped with an ultra-filtration (UF) membrane with a molecular weight cut off of $10 \mathrm{kDa}$ (YM-10; Millipore, Bedford, MA). After that, trichloroacetic acid (TCA) was added to the 
concentrated solutions so that the final concentration was $10 \%(\mathrm{w} / \mathrm{v})$. The precipitation steps were performed on ice for $1 \mathrm{~h}$, and the precipitates were recovered by centrifugation $(15,000$ $\mathrm{rpm} ; 5 \mathrm{~min})$. The protein pellets were then washed twice in $80 \%(\mathrm{v} / \mathrm{v})$ ice-cold acetone. The dried protein pellets were resuspended in $50 \mu \mathrm{L}$ of sample solubilization buffer comprising 5 M urea, $1 \mathrm{M}$ thiourea, 1\% (w/v) CHAPS, $1 \%(\mathrm{w} / \mathrm{v})$ Triton X-100, and 1\% (w/v) dithiothreitol (DTT) and placed on a vortex shaker. The samples were then centrifuged at 15,000 rpm for 30 min to remove suspended matter in the solubilization buffer.

\subsection{D-PAGE separation}

For first-dimension separation, $75 \mathrm{~mm}$ immobilized $\mathrm{pH}$ gradient (IPG) strips (AgarGEL with a $\mathrm{pH}$ range of 3-10; Atto Corporation, Tokyo, Japan) were placed in an isoelectric focusing (IEF) unit (discRun, Atto Corporation, Tokyo, Japan) and focused for 210 min with a constant voltage of $350 \mathrm{~V}$. Following IEF, proteins were fixed by soaking the strips in $2.5 \%$ TCA solution. After that, the strips were equilibrated with a solution comprising $50 \mathrm{mM}$ Tris- $\mathrm{HCl}$, $\mathrm{pH}$ 6.8, 2\% SDS, and 0.001\% bromophenol blue (BPB) for $10 \mathrm{~min}$. Strips were then loaded onto cast $12.5 \%$ polyacrylamide gels (E-D12.5L, Atto Corporation, Tokyo, Japan) and electrophoresis was performed at $40 \mathrm{~mA}$ for $90 \mathrm{~min}$. The gels were stained with Coomassie Brilliant Blue (EzStain AQua; Atto, Tokyo, Japan).

\section{Results and discussion}

\subsection{Development of membrane fouling in the pilot run}

Figure 1 plots the changes in total filtration resistance determined for the two MBRs. The crosses in the figure represent the filtration resistances recorded just after physical membrane cleaning, and the line connecting those crosses (dashed line in Figure 1) shows the development of physically irreversible fouling. As indicated in the figure, the total filtration resistance in MBR1, which was operated with a short SRT, increased much faster than that in MBR2. In MBR1, physical membrane cleaning was conducted on days 9 and 12. However, it did not reduce filtration resistance to a value recorded at the beginning of the continuous operation. This indicates that physically irreversible fouling was also significant in MBR1. In contrast, the development of both types of membrane fouling was minimal in MBR2 (long SRT).

Similar results have been reported in a number of previous studies investigating membrane fouling in MBRs treating real wastewater $[4,13,14]$. Kimura et al. reported that
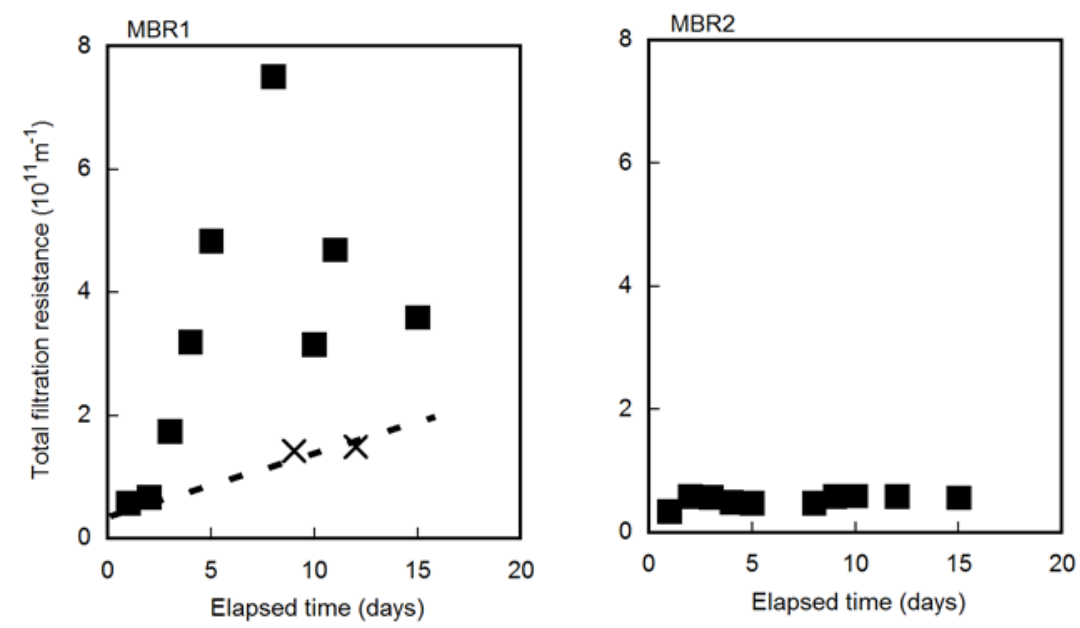

Figure 1. Changes in total filtration resistance during the continuous operation. 
the characteristics of soluble microbial products (SMP) differed depending on SRT [15]. The development of membrane fouling would be affected by differences in the properties of SMP. At present, however, little is known about differences in the nature of organic matter contained in mixed liquor suspension that are caused by differences in the operating conditions of MBRs. Consequently, the detailes on how differences in organic contents in mixed liquor suspensions affect the development of membrane fouling remain unclear. Therefore, we analyzed protein profiles of the organic matter contained in mixed liquor suspension and the foulant extracted at the end of the continuous operation. The relationship between the nature of proteins and their fouling propensities will be discussed in the following sections.

3.2 2D-PAGE gel images of dissolved organic matter contained in mixed liquor and foulants extracted from fouled membranes

Figure 2 shows 2D-PAGE gel images of dissolved organic matter contained in mixed liquor suspension. By comparing the gel images, it is apparent that the spotting patterns of dissolved organic matter collected from MBR1 and MBR2 were totally different. While most proteins in the dissolved organic matter of MBR2 appeared in the $\mathrm{pH}$ 4-6 region, the relative dominance of proteins that appeared in the $\mathrm{pH}$ 6-8 region was high in the dissolved organic matter collected from MBR1. These results indicate that the natures of major proteins in the mixed liquor suspension differed considerably depending on the operating conditions. This difference cannot be discovered by building block analyses (e.g., monosaccharide or amino acid compositions) or spectroscopic analyses (e.g., Fourier transform infrared (FTIR) or excitation-emission matrices (EEM) spectra analyses).

Figure 3 shows 2D-PAGE gel images of foulants extracted from the fouled membranes. As with 2D-PAGE analysis of dissolved organic matter contained in mixed liquor suspension, spotting patterns of the extracted foulants differed considerably depending on the operating conditions. However, the trends in the protein profiles in the extracted foulants were totally different from that in the dissolved organic matter in the mixed liquor suspension. In MBR1, proteins with an isoelectric point in the acidic region (range $\mathrm{pH}$ 3-5) were dominant, whereas most proteins appeared in the neutral region (range $\mathrm{pH}$ 5-7) in the foulant extracted from MBR2. We previously reported that characteristics of foulants differed depending on the operating conditions (e.g., SRT, membrane flux, membrane material) [4,6,11], but information on the differences in the nature of foulants caused by differences in operating conditions has not been available. The results obtained in this study clearly indicate that the nature of the foulants was different depending on the operating conditions. The dominant fouling mechanism was apparently different in these two MBRs. This will be discussed in the next section.

\subsection{Comparison of 2D-PAGE gel images of dissolved organic matter in mixed liquor suspension and extracted foulants}

As presented in Figures 2 and 3, the spotting patterns in the 2D-PAGE gels of the dissolved organic matter and the extracted foulants differed considerably. A direct linkage, however, could not be found between the difference in protein profiles of dissolved organic matter in the mixed liquor suspension and that of the extracted foulant. It is apparent that some proteins contained in the mixed liquor suspension are more likely to cause membrane fouling. In MBR2 (long SRT), the presence of proteins that appeared in the neutral $\mathrm{pH}$ range in the extracted foulant was more pronounced than that in the dissolved organic matter. Since the $\mathrm{pH}$ of the mixed liquor suspension during the continuous operation was in the range of 6-7, electric charges of proteins with an isoelectric point in the neutral $\mathrm{pH}$ range were likely to be 

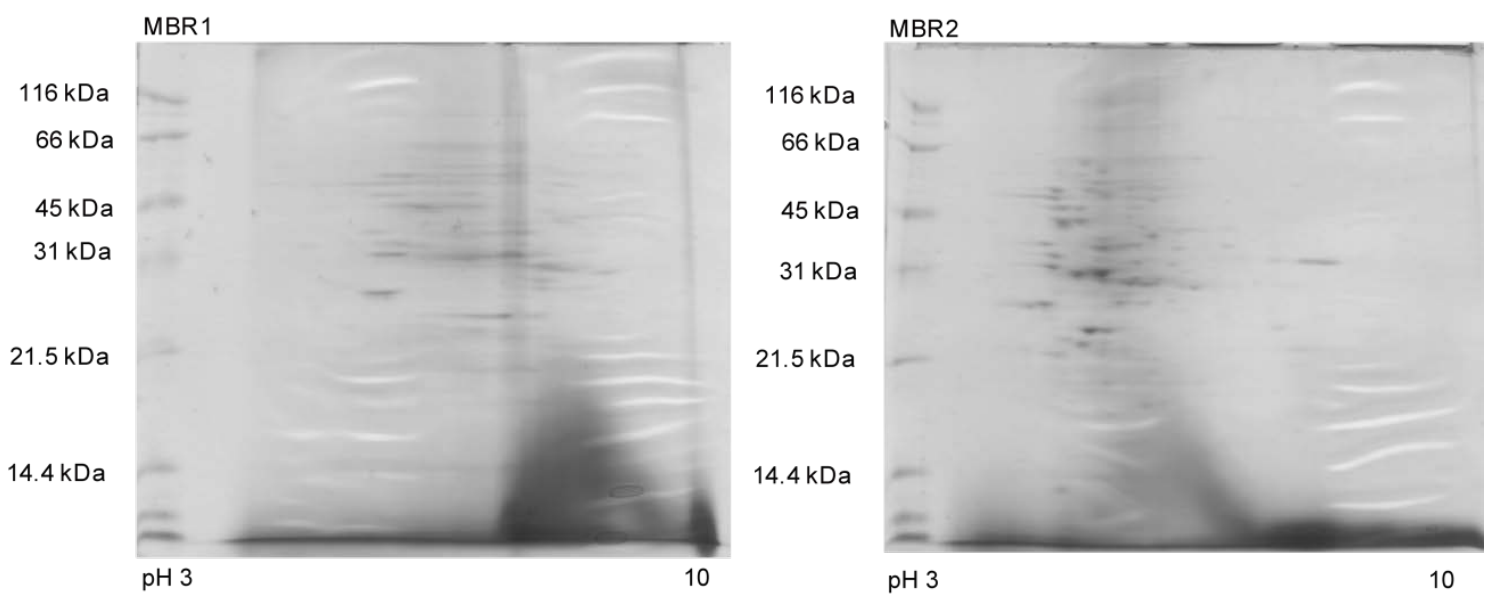

Figure 2. 2D-PAGE images of dissolved organic matter contained in mixed liquor suspension of pilot-scale MBRs. Protein sample loading: MBR1, $200 \mu \mathrm{g} ;$ MBR2, 210 $\mu \mathrm{g}$.
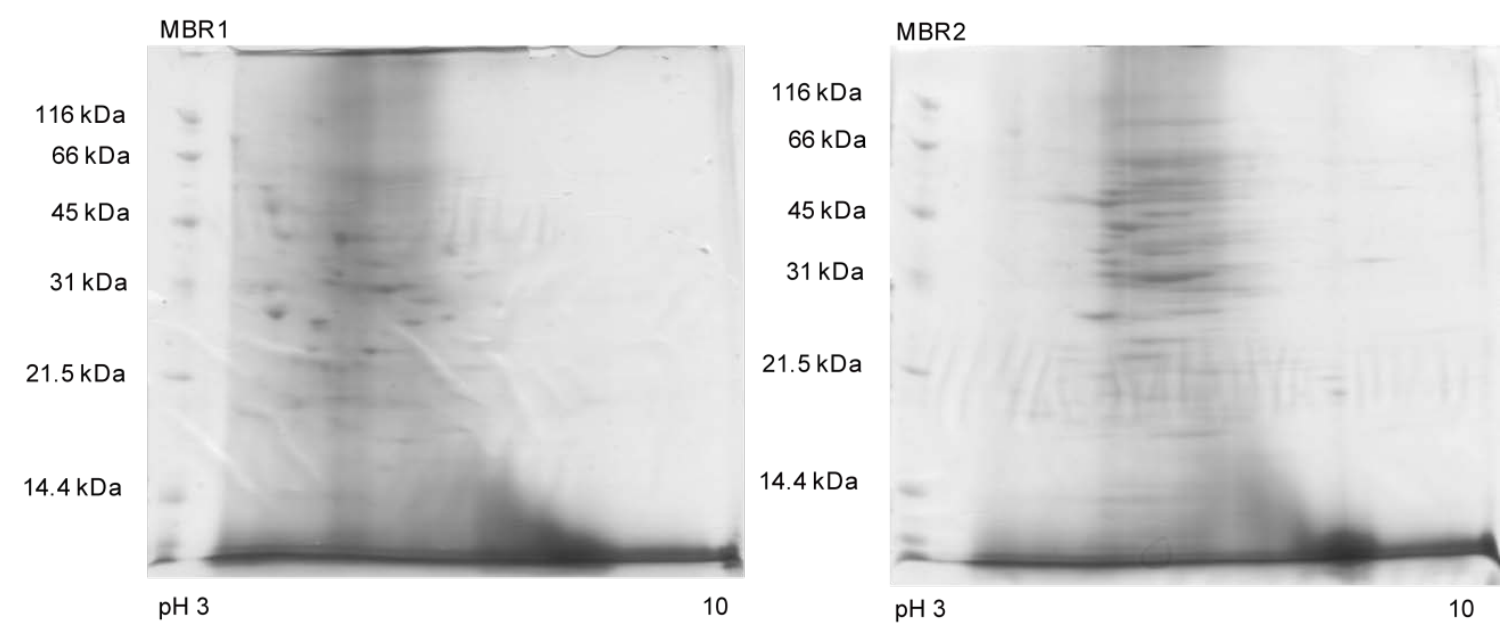

Figure 3. 2D-PAGE images of foulants extracted from fouled membranes. Protein sample

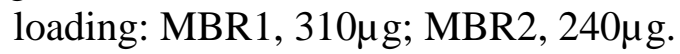

less significant. Solubilities of proteins tend to decrease at their isoelectric points. Therefore, the proteins with isoelectric points in the neutral $\mathrm{pH}$ range were thought to have a higher propensity to cause membrane fouling through adsorption onto the membranes in the MBRs examined in this study. This would be a good explanation as to why these proteins were more abundant in the extracted foulant.

In MBR1 (short SRT), however, the trend in the difference between the protein profiles of the extracted foulant and the dissolved organic matter contained in the mixed liquor suspension was totally different from that in MBR2. Proteins that appeared in the acidic $\mathrm{pH}$ region ( $\mathrm{pH}$ 35) were more abundant in the extracted foulant compared with the dissolved organic matter in the mixed liquor suspension. Since these proteins have negative charges in the mixed liquor suspension, their high affinities to the membrane could not be explained by the decrease in solubilities of proteins at their isoelectic points. The higher fouling propensities of the major proteins extracted from MBR1 could not be explained by their charges as well. The 
membrane used in this study had a negative charge (zeta potential of $-25.2 \mathrm{~V}$ ) in the $\mathrm{pH}$ range in the continuous operation. Therefore, constituents that have negative charges are less likely to approach the membrane due to the charge repulsion.

We do not have a clear explanation for the differences between the protein profiles of the extracted foulant and the dissolved organic matter contained in the mixed liquor suspension in MBR1 at present. One possibility is that the main fouling mechanism in MBR1 was pore blocking. The membrane fouling mainly caused by pore blocking might be attributed to particles with particle sizes that were similar to the pore size of the membrane. These particles are thought to form as a result of interactions occurring among many organic/inorganic compounds in the mixed liquor suspension of MBRs. Therefore, if pore blocking is the main mechanism for the development of membrane fouling, properties of the resulting particles rather than those of individual organic compounds might be more important for the discussion of their fouling propensities. If we take into account the results of continuous operation of pilot-scale MBRs that indicated the pronounced development of membrane fouling in MBR1, it is thought that information on the fouling mechanisms in MBR1 would be more important for controlling membrane fouling in the long-term operation of a real MBR. Identification of the origins, properties, or functions of major proteins extracted from MBR1 through structural analyses would give us useful information regarding possible interactions or properties of resulting particles. Further investigation regarding this point is needed.

\section{Conclusions}

We investigated the relationship between the nature of proteins and their fouling propensities in pilot-scale MBRs treating municipal wastewater by means of 2D-PAGE, in which proteins are separated with both an isoelectric point and a molecular weight. Two identical pilot-scale submerged MBRs were operated under different SRTs to investigate the effect of operating conditions on the types of protein with higher fouling propensities. Although, protein profiles of the extracted foulant were considerably different from that of the dissolved organic matter contained in the mixed liquor suspension, the trends in the difference in protein profiles differed depending on the operating conditions. In MBR2 (long SRT), the presence of proteins that appeared in the neutral $\mathrm{pH}$ range was more pronounced in the extracted foulant. Since $\mathrm{pH}$ in the continuous operation was in the range of 6-7, the difference in protein profiles between the extracted foulant and organic matter contained in the mixed liquor suspension in MBR2 would be explained by the decrease in solubilities of proteins at their isoelectric points. In MBR1 (short SRT), proteins that appeared in the acidic $\mathrm{pH}$ region ( $\mathrm{pH}$ 3-5) were more prominent in the extracted foulant. The results obtained in this study implied that the dominant fouling mechanism in MBR1 was different from that in MBR2. Since membrane fouling was more significant in MBR1, which was operated with a short SRT, investigation of the dominant fouling mechanism in MBR1 would be important for controlling membrane fouling in MBRs. Analyses of the origins, properties, or functions of major proteins extracted from MBR1 would give us useful information for the discussion on this topic. Further study regarding this point is therefore necessary.

\section{References}

[1] S. Judd, The MBR Book: Principles and Applications of Membrane Bioreactors in Water and Wastewater Treatment. Elsevier, Oxford, 2006.

[2] T. Stephenson, S. Judd, B. Jefferson and K. Brindle, Membrane bioreactors for wastewater treatment. IWA publishing, London, 2000. 
[3] U. Metzger, P. Le-Clech, R. M. Stuetz, F. H. Frimmel and V. Chen, Characterization of polymeric fouling in membrane bioreactors and the effect of different filtration modes. J. Membr. Sci. 301 (2007) 180-189.

[4] T. Miyoshi, T. Tsuyuhara, R. Ogyu, K. Kimura and Y. Watanabe, Seasonal variation in membrane fouling in membrane bioreactors (MBRs) treating municipal wastewater. Water Res. 43 (2009) 5109-5118.

[5] S. Liang and L. Song, Characteristics and fouling behavioirs of dissolved organic matter in submerged membrane bioreactor systems. Environ. Eng. Sci. 24 (2007) 652-662.

[6] K. Kimura, T. Miyoshi, T. Naruse, N. Yamato, R. Ogyu and Y. Watanabe, The difference in characteristics of foulants in submerged MBRs caused by the difference in the membrane flux. Desalination 231 (2008) 268-275.

[7] P. Wilmes and P. L. Bond, The application of two-dimensional polyacrylamide gel electrophoresis and downstream analyses to a mixed community of prokaryotic microorganisms. Environ. Microb. 6(9) (2004) 911-920.

[8] P. Wilmes and P. L. Bond, Towards exposure of elusive metabolic mixed-culture processes: the application of metaproteomic analyses to activated sludge. Water Sci. Technol. 54(1) (2006) 217-226.

[9] K. Kimura, R. Nishisako, T. Miyoshi, R. Shimada and Y. Watanabe, Baffled membrane bioreactor (BMBR) for efficient nutrient removal from municipal wastewater. Water Res. 42 (2008) 625-632.

[10] I. S. Chang, P. Le-Clech, B. Jefferson and S. Judd, Membrane fouling in membrane bioreactors for wastewater treatment. J. Environ. Eng. 128 (2002) 1018-1029.

[11] N. Yamato, K. Kimura, T. Miyoshi and Y. Watanabe, Difference in membrane fouling in membrane bioreactors (MBRs) caused by membrane polymer materials. J. Membr. Sci. 280 (2006) 911-919.

[12] T. Miyoshi, T. Aizawa, K. Kimura and Y. Watanabe, Metaproteomic analysis of proteins causing physically irreversible fouling in membrane bioreactors (MBRs), In Proceedings of Membranes in Drinking and Inductrial Water Treatment, Trondheim, 2010.

[13] S. Rosenberger, C. Laabs, B. Lesjean, R. Gnirss, G. Amy, M. Jekel and J. -C. Schorotter, Impact of colloidal and soluble organic material on membrane performance in membrane bioreactors for municipal wastewater treatment. Water Res. 40 (2006) 710-720.

[14] H. Y. Ng, T. W. Tan and S. L. Ong, Membrane fouling of submerged membrane bioreactors: impact of mean cell residence time and the contributing factors. Environ. Sci. Technol. 40 (2006) 2706-2713.

[15] K. Kimura, T. Naruse and Y. Watanabe, Changes in characteristics of soluble microbial products in membrane bioreactors associated with different solid retention times: Relation to membrane fouling. Water Res. 43 (2009) 1033-1039. 